\title{
Preparation and Performance Testing of SBS Modified Bitumens Reinforced with Halloysite and Sepiolite Nanoclays
}

\author{
Dilay UNCU ${ }^{1}$ \\ Ali TOPAL ${ }^{2}$ \\ Mehmet Özgür SEYDİBEYOĞLU ${ }^{3}$
}

\begin{abstract}
In this study, halloysite and sepiolite nanoclays were used to reinforce SBS modified bitumens. The nanoclays used are different from the materials in the literature and have properties such as easy to find, economical and available from local sources. The mixing parameters were determined before production process. The polymer additive SBS was added into base bitumen at $3 \%$ and $5 \%$, while the nanoclay additives were added into polymer modified bitumen at $2 \%$ and $4 \%$ ratios. The morphological structures were investigated under fluorescence microscope. Physical and rheological properties of the samples were compared. The phase separation cases were investigated by storage stability test. Furthermore, rutting performance of samples was measured with zero shear viscosity (ZSV) and multi stress creep recovery (MSCR) test methods.
\end{abstract}

Keywords: Polymer modified bitumen, halloysite, sepiolite, dynamic shear rheometer, zero shear viscosity, multiple stress creep recovery.

\section{INTRODUCTION}

Bitumen is a mixture of aliphatic, aromatic, and naphthenic hydrocarbons and it is commonly used in construction of roads [1]. Several types of failures (rutting, fatigue cracking and thermal cracking) occur during the service life of asphalt pavements [2]. Bitumen is provided to increase the low and high temperature performance, and to provide elasticity, and to reduce permanent deformation by using various additives [3]. Modification of bitumen improves

Note:

- This paper was received on February 3, 2020 and accepted for publication by the Editorial Board on November 9, 2020.

- Discussions on this paper will be accepted by May 31, 2020.

- https://doi.org/10.18400/tekderg.683568

1 Manisa Celal Bayar University, Department of Civil Engineering, Manisa, Turkey - dilay.yildirim@cbu.edu.tr https://orcid.org/0000-0001-8660-2114

2 Dokuz Eylül University, Department of Civil Engineering, İzmir, Turkey - ali.topal@deu.edu.tr https://orcid.org/0000-0002-2601-1926

3 İzmir Katip Çelebi University, Department of Material Science and Engineering, İzmir, Turkey ozgur.seydibeyoglu@ikc.edu.tr - https://orcid.org/0000-0002-2584-7043 
performance properties like oxidation, aging resistance, temperature sensitivity, adhesion, durability, rutting, and fatigue resistance $[4,5,6]$.

In recent years, polymers having very long chain molecules consisting of several ordered small molecules, are used for the modification of bitumen [7]. The prevalent used polymers from the group of elastomeric block copolymers [8] and Styrene-Butadiene-Styrene (SBS) belongs to this group enhances the elasticity of bitumen. However, weak compatibility between SBS and bitumen causes separations especially at high storage temperatures. Thus, when the modified bitumen is exposed to heat, ultraviolet light and oxygen, the separation becomes even worse due to the unsaturated bonds in SBS $[9,10,11]$. The search for new additives has been done to eliminate this problem. Recently, nanomaterials as new additives have been used in many engineering fields.

At least one dimension of nanomaterials is between 1 and 100 nanometers. Nanomaterials show better and varied properties according to normal sized materials by means of high surface area and their small size [12]. Significant development is obtained in mechanical, thermal and barrier properties of bitumen by addition of several nanomaterials for modification $[10,13]$. Furthermore, the rutting resistance and fatigue cracking are improved by usage of nanomaterials in bitumen and bituminous mixtures according to some researches in the literature [12].

Nanomaterials are used as additives in polymer modified bitumens (PMB) and also used alone for modification. The parameters like type of nanomaterials, ratios of additives, mixing method and conditions are used in these studies vary. According to the studies, 3-6\%, 2-5\% and $3-7 \%$ ratios of SBS are commonly used $[10,13,14]$. When the studies are examined, it is seen that nanoclays are mostly used as nanomaterial additives and the use of montmorillonite, which belongs to smectite clay group that the distance between layers is high, is quite common among nanoclays $[10,15,16,17]$. The reasons for preference of nanoclays are easily attainability from natural sources and being economic. The usage percentages of nanoclays are $2 \%, 3 \%$ and $4 \%$ in general $[14,15,18,19]$. Nanoclay addition solves separation, storing and transportation problems with reducing the density difference between bitumen and polymer [10, 20]. In addition, it has been observed that with this modification process, there are significant improvements in the thermal, mechanical and barrier properties of bituminous binders $[10,12,13]$. The reason for this improvement is that nanomaterials show different and superior properties due to their small sizes and high surface areas compared to other normal sized materials [12].

The properties of the samples were researched by conventional methods and compared with each other. The morphological structures of modified bitumen samples were investigated under fluorescence microscope. The rheological properties were utilized by DSR. The upper critical temperatures determined according to the Superpave Performance Grading (PG) system for base and modified bitumen samples using rutting parameter $\left(\mathrm{G}^{*} / \sin \delta\right)$. The loading and temperature effects on the unaged and aged bitumens performance were analysed at five different temperatures from $40^{\circ} \mathrm{C}$ to $80^{\circ} \mathrm{C}$ with $10^{\circ} \mathrm{C}$ increment at low frequency $(0.01 \mathrm{~Hz})$ and high frequency $(10 \mathrm{~Hz})$ levels. Rutting performances of all bitumen samples were also investigated with zero shear viscosity (ZSV) and multiple stress creep recovery (MSCR) tests. 


\section{EXPERIMENTAL}

\subsection{Materials}

The base bitumen with a penetration grade of 50/70 was procured from Tupras Refinery, Aliaga/Izmir. Penetration [21] softening point [22], viscosity [23], rolling thin film oven test [24] and, in addition, penetration, softening point tests after RTFOT [21, 22] were performed as conventional test methods for characterizing the properties of the base bitumen. Brookfield Viscometer was used for viscosity test results at $135^{\circ} \mathrm{C}$ and $165^{\circ} \mathrm{C}$. The results obtained from these tests are presented in Table 1.

Table 1 - The properties of the base bitumen

\begin{tabular}{|c|c|c|c|}
\hline Test & Specification & Results & Specification limit \\
\hline $\begin{array}{l}\text { Penetration }\left(25^{\circ} \mathrm{C} ; 0.1\right. \\
\mathrm{mm})\end{array}$ & ASTM D5 & 65 & $50-70$ \\
\hline Softening point $\left({ }^{\circ} \mathrm{C}\right)$ & ASTM D36 & 53.7 & $46-54$ \\
\hline Viscosity at $135^{\circ} \mathrm{C}$ (cP) & ASTM D4402 & 425 & - \\
\hline Viscosity at $165^{\circ} \mathrm{C}(\mathrm{cP})$ & ASTM D4402 & 112.5 & - \\
\hline $\begin{array}{l}\text { Rolling thin film oven } \\
\text { test (RTFOT) }\end{array}$ & ASTM D2872 & & \\
\hline Change of mass $(\%)$ & & 0.16 & 0.5 (max.) \\
\hline $\begin{array}{l}\text { Retained penetration } \\
(\%)\end{array}$ & ASTM D5 & 82 & 50 (min.) \\
\hline $\begin{array}{l}\text { Softening point after } \\
\text { RTFOT }\left({ }^{\circ} \mathrm{C}\right)\end{array}$ & ASTM D36 & 58.3 & 48 (min.) \\
\hline Flash point $\left({ }^{\circ} \mathrm{C}\right)$ & ASTM D92 & 334 & 230 (min.) \\
\hline
\end{tabular}

Kraton $^{\circledR}$ D1101 is used as a modifier of bitumen for roads. The SBS block copolymers are composed of blocks of styrene and butadiene and the properties belong to SBS in this study are seen in Table 2.

In this paper, halloysite and sepiolite were used for reinforcing PMB with a high shear mixer. These are two different Turkish natural clays that are abundant in Turkish mines and they have two different distinct shapes at the nanoscale. Sepiolite is a needle like structure that can reinforce the matrix. The other clay Halloysite is natural clay that has tubular structure at the nanoscale. The morphology is different and thus the rheology and the asphalt reinforcement are different compared to sepiolite. These two clays are close in chemical composition to layered clays like montmorillonite. In this study these two nanoclays were used as alternative additives for modification.

The above mentioned nanoclays were supplied from ESAN Company for adding into PMB and producing nanocomposites. The contents of halloysite and sepiolite nanoclays are depicted in Table 3 and 4. 
Table 2 - Typical properties of Kraton ${ }^{\circledR}$ D1101 SBS [25]

\begin{tabular}{lccc}
\hline Property & Test Method & Units & $\begin{array}{c}\text { Typical } \\
\text { Value }\end{array}$ \\
\hline Elongation at break & ISO 37 & $\%$ & 880 \\
\hline Tensile strength & ISO 37 & Mpa & 33 \\
\hline Specific gravity & ISO 2781 & & 0.94 \\
\hline Hardness, shore $\mathbf{A}(\mathbf{3 0}$ sec) & ISO 868 & $\begin{array}{c}\text { Hardness, Shore A } \\
(30 \mathrm{sec})\end{array}$ & 72 \\
\hline $\mathbf{3 0 0 \%}$ Modulus & ISO 37 & $\mathrm{MPa}$ & 2.9 \\
\hline Melt flow ratio, $\mathbf{2 0 0}^{\circ} \mathbf{C} / \mathbf{5 k g}$ & ISO 1133 & $\mathrm{g} / 10 \mathrm{~min}$. & $<1$ \\
\hline Bulk density & $\begin{array}{c}\text { ASTM D 1895 } \\
\text { method B }\end{array}$ & $\mathrm{kg} / \mathrm{dm}^{3}$ & 0.4 \\
\hline
\end{tabular}

Table 3 - Chemical analysis of halloysite

\begin{tabular}{cccccccccc}
\hline \multirow{2}{*}{ Content } & $\begin{array}{c}\mathrm{AZ} . \\
(\mathrm{Lol})\end{array}$ & $\mathrm{SiO}_{2}$ & $\mathrm{Al}_{2} \mathrm{O}_{3}$ & $\mathrm{Fe}_{2} \mathrm{O}_{3}$ & $\mathrm{TiO}_{2}$ & $\mathrm{CaO}$ & $\mathrm{MgO}$ & $\mathrm{Na}_{2} \mathrm{O}$ & $\mathrm{K}_{2} \mathrm{O}$ \\
\hline \multirow{2}{*}{$(\%)$} & 16.50 & 43.00 & 37.50 & 0.70 & 0.10 & 0.10 & 0.15 & 0.05 & 0.30 \\
& \pm 1.00 & \pm 1.50 & \pm 1.50 & \pm 0.10 & \pm 0.05 & \pm 0.05 & \pm 0.05 & \pm 0.01 & \pm 0.05 \\
\hline
\end{tabular}

Table 4 - Chemical analysis of sepiolite

\begin{tabular}{ccccccccc}
\hline Content & $\mathrm{SiO}_{2}$ & $\mathrm{Al}_{2} \mathrm{O}_{3}$ & $\mathrm{Fe}_{2} \mathrm{O}_{3}$ & $\mathrm{TiO}_{2}$ & $\mathrm{CaO}$ & $\mathrm{MgO}$ & $\mathrm{Na}_{2} \mathrm{O}$ & $\mathrm{K}_{2} \mathrm{O}$ \\
\hline$(\%)$ & 18.45 & 0.84 & 0.218 & 0.029 & 21.64 & 22.27 & 0.13 & 0.11 \\
\hline
\end{tabular}

\subsection{Preparation of Samples}

The samples were produced by a high shear mixer at $180^{\circ} \mathrm{C}$ and $2000 \mathrm{rpm}$. In this method SBS was added into the base bitumen and mixed for 15 minutes firstly. Then halloysite and sepiolite were added into the mixture and mixed for 45 minutes more. These production parameters were determined in the light of the literature as a result of viscosity measurements. $3 \%$ and $5 \%$ ratios were selected for SBS as the weight of the base bitumen according to minimum and maximum ratios in the literature $[26,27]$ and similarly nanoclays were used at $2 \%$ and $4 \%$.

\subsection{Test Methods}

\subsubsection{Conventional Bitumen Tests}

The conventional bitumen tests were implemented for bitumen samples. Penetration [21], softening point [22], viscosity [23], storage stability [28], rolling thin film oven test (RTFOT) 
[24], and in addition, penetration and softening point after RTFOT were applied on all samples. The results of viscosity were measured at $135^{\circ} \mathrm{C}$ and $165^{\circ} \mathrm{C}$.

\subsubsection{Morphological Structure}

Fluorescent microscope was operated for investigating the morphological structure of the samples. The morphology term is used to define the properties of microstructure between bitumen and polymer [29]. Fluorescent microscopy helps to understand the morphologic structure of samples by examining the quality of the dispersion. The working principle of fluorescent microscopy is that polymers swell due to absorption of some of the components of the base bitumen under fluoresce in ultraviolet light. The bitumen phase looks dark or black and the polymer phase seems light [30]. Leica DMEP fluorescent microscope was used for investigating the images of all modified bitumen samples.

\subsubsection{Rheological Test Methods}

Dynamic rheological tests were applied to define the viscous and elastic behaviour of bitumen samples by using DSR. The tests were implemented with parallel plates and the diameter of plates was $25 \mathrm{~mm}$ with $1 \mathrm{~mm}$ gap. The unaged and RTFOT aged samples are subjected to DSR tests.

The viscous and elastic behaviour of bitumen as represented by the complex shear modulus $\left(G^{*}\right)$, shear storage modulus $\left(G^{\prime}\right)$, shear loss modulus ( $\left.G^{\prime \prime}\right)$ and phase angle $(\delta)$ are measured by DSR. Rutting and fatigue behaviours are represented with $G^{*}$ and $\delta$. The $G^{*} / \sin \delta$ and $\mathrm{G}^{*} \cdot \sin \delta$ are defined as rutting resistance and fatigue cracking performance parameters respectively [24].

Lately, it has been stated that $\mathrm{G}^{*} / \sin \delta$ parameter is not efficient and unsuccessful for predicting the rutting performance. For this reason, as an alternative to $\mathrm{G}^{*} / \sin \delta$, the value of zero shear viscosity is recently used. ZSV is the viscosity measured in shear deformation, when the shear rate approaching zero [25]. In this study, determination of ZSV was performed by the implementation of creep test.

In this creep test, a constant shear strain is applied to the bitumen sample, and the exiting strain is observed for a prespecified period of time. If the stress is applied for a sufficient period, the bitumen deformation rate takes a constant value corresponding to the steady state flow of bitumen. At this stage, the viscosity is determined as the steady state viscosity or the ZSV [26]. The ZSV values have been estimated by implementation of creep test at $60^{\circ} \mathrm{C}$ and the test was carried out according to CEN/TS 15325 standard [27]. The creep test geometry is composed of $25 \mathrm{~mm}$ parallel plates. The gap between the plates is $1 \mathrm{~mm}$. The value of stress is $10 \mathrm{~Pa}$ for base bitumen and $30 \mathrm{~Pa}$ for modified bitumens. Each creep test proceeds for 30 minutes. Time-creep and time-creep compliance graphs are obtained at the end of the test. When it reaches steady state, the curve of time-creep compliance becomes closer to the line. The slope of the time-creep compliance curve in the last 15 minutes ( 900 seconds) before removing the load is calculated by the following Eq. (1) with the average slope $\Delta t / \Delta \mathrm{J}$ stable viscosity value is zero shear viscosity. 
$Z S V=\Delta t / \Delta J=900 /\left(J_{f}-J_{15}\right)$

In Eq. (1) $\mathrm{J}_{15}$ symbolizes the compliance stated in $\mathrm{Pa}^{-1}$, measured last 15 minutes before removing the loading, $\mathrm{J}_{\mathrm{f}}$ is the compliance stated in $\mathrm{Pa}^{-1}$, measured at the end of the 30 minutes. The expression 900 is indicated the time interval between the two measurements as seconds [28].

The latest development to the Superpave Performance Graded (PG) Asphalt Binder specification is the multiple stress creep and recovery (MSCR) test. DSR is used for the test and the test is applied to short term aged samples [29]. The MSCR test was performed according to ASTM D7405-08 standard [30]. $25 \mathrm{~mm}$ parallel plates with $1 \mathrm{~mm}$ gap and $60^{\circ} \mathrm{C}$ temperature value are used for the test. The bitumen sample is exposed to creep loading and unloading cycle of $1 \mathrm{~s}$ and $9 \mathrm{~s}$, at $100 \mathrm{~Pa}$ and $3200 \mathrm{~Pa}$ stress levels and 10 cycles for both stress levels. Two main parameters, the non-recoverable creep compliance $\left(\mathrm{J}_{\mathrm{nr}}\right)$ and percent recovery (\%rec), are calculated from the test results for evaluating the rutting sensibility. The difference in $\mathrm{J}_{\mathrm{nr}}$ between two stress levels is calculated to detect the stress sensibility of the sample and expressed as percentage $\mathrm{J}_{\mathrm{nr} \text {,diff. }}$

\subsection{Result and Discussions}

\subsubsection{Conventional Test Results}

The conventional properties of the samples are presented in Table 5. In the table, halloysite and sepiolite were shortened as "Hal" and "Sep" respectively.

The test results of conventional bitumen tests indicated that all modified samples had a remarkable decline in penetration and increment in temperature of softening point according to base bitumen. Table 5 shows decline in penetration values and an increment in softening point temperature especially for 3\% SBS and nanoclay modified bitumen samples. A less decrease in penetration value is identified for 5\% SBS and modified bitumen samples reinforced with nanoclay. Softening point temperatures of 5\% SBS $+2 \% \mathrm{Hal}$ and $5 \% \mathrm{SBS}+$ $2 \%$ Sep modified bitumen are lower than 5\% SBS modified bitumen, 5\% SBS $+4 \%$ Hal and $5 \%$ SBS $+4 \%$ Sep modified bitumen have close values with 5\% SBS modified bitumen. After short term aging, a decrease is observed in penetration values in all samples except 3\% SBS $+2 \%$ Sep and 3\% SBS $+4 \%$ Sep modified bitumen. In softening point temperatures after short term aging, 3\% SBS and nanoclay modified bitumen samples have lower values according to $3 \%$ SBS modified sample. It is thought that nanoclays prevent aging of PMB due to complicated oxygen diffusion. In 5\% SBS and nanoclay modified bitumen samples, softening point temperatures increased except $5 \%$ SBS $+2 \%$ Sep modified bitumen. It is predicted that the amount of nanoclays has been insufficient and properties of polymer has become dominant.

The flow resistances of all samples were obtained by viscosity values. The viscosity test results are lower at high temperature values because the bitumen samples became more viscous. All modified bitumen samples had high viscosity values according to the base bitumen for both temperatures. The addition of 3\% SBS roughly increased the viscosity values two times and the addition of 5\% SBS increased viscosity four times. The nanoclay 


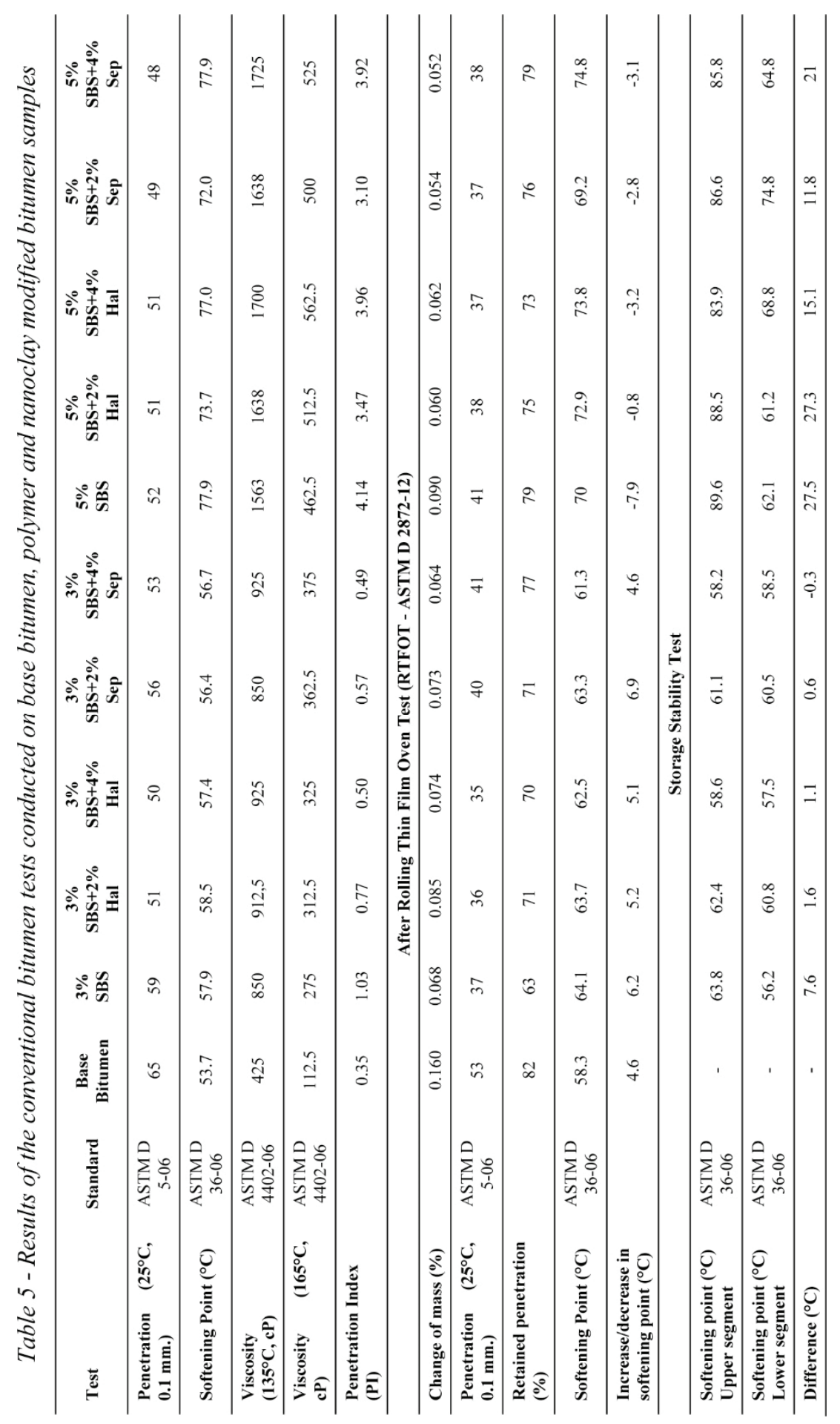


addition into the PMB also increased the viscosity values. The 3\% SBS $+4 \%$ Sep has the highest viscosity for two temperatures between 3\% SBS and nanoclay modified bitumens. The $5 \%$ SBS $+4 \%$ Sep has the highest viscosity at $135^{\circ} \mathrm{C}$ and the $5 \% \mathrm{SBS}+4 \%$ Hal has the highest viscosity at $165^{\circ} \mathrm{C}$ between $5 \%$ SBS and nanoclay modified bitumens. The increment in viscosity is permitted in the specification up to $3000 \mathrm{mPa} \mathrm{s}$ at $135^{\circ} \mathrm{C}$. The reason of the limitation is that the too high viscosity values negatively affect the bitumen workability. When the results of the viscosity test are examined, this undesirable situation isn't occurring for any samples.

The penetration index value expresses the temperature sensitivity of the bituminous binder and there is an inverse proportion between them. Increase of penetration index is an indicator about decrease of sensitivity to temperature. Penetration Index value less than -2 indicates that bitumen is very sensitive to temperature, and the value greater than +2 indicates that it is less sensitive to temperature [38]. The penetration indexes of all modified bitumen samples increased compared to base bitumen, so their sensitivity to temperature decreased. The polymer additive is more effective in decreasing the temperature sensitivity compared to the penetration index values, and the increase in the additive ratio decreased the sensitivity.

The lower storage stability values are better and it is desirable that the difference in softening point between the upper and lower does not exceed $5^{\circ} \mathrm{C}$ in the specification. When the test results of the modified bitumens are examined, the storage stability values are improved by adding nanoclay into the SBS modified bitumen. Only the storage stability of the SBS modified bitumen sample was above the limit value in the 3\% SBS modified group, and the addition of nanoclays reduced the storage stability values to below the limit value of $5^{\circ} \mathrm{C}$. The bitumen samples containing sepiolite have lower storage stability values than the bitumen samples containing halloysite. All the samples are seen to exceed the limit value in $5 \%$ SBS modified group due to the increase in the percentage of polymer. The storage stability values worsen as the percentage of polymer increases. In the previous studies in the literature, it is found that the increase in the amount of polymer negatively affects the storage stability [39, 40, 41] and it is stated that storage stability of polymer modified asphalts depends on many factors, especially asphalt composition, polymer characteristics and content [39]. However, with the addition of nanoclay, the storage stability values did not fall below the limit value, but lower values were obtained.

\subsubsection{Examination of Morphological Structure}

Thin section specimens were taken after completion the production of all modified bitumens. The specimens were examined under fluorescence microscopy and the information of the additives distribution in the bitumen phase was obtained. Dispersion of thin section specimens between lame and lamella of modified bitumens containing nanoclays has become more difficult, so this situation overlaps with increasing viscosity values.

When only the polymer modified sample in Figure 1.a is examined from the $3 \%$ modified bitumen samples, it is seen that the polymers have spread to the bitumen phase but formed thin bond structures. These bonds have gained volume and have spread to more areas in the bitumen phase with the addition of nanoclays in Figure 1.b, $\mathrm{c}$ and $\mathrm{d}$. The microscope image of $3 \%$ SBS $+4 \%$ Sep modified bitumen sample cannot be obtained because of insufficient dispersion amount, so polymers and nanoclays cannot be distinguished in the image. 

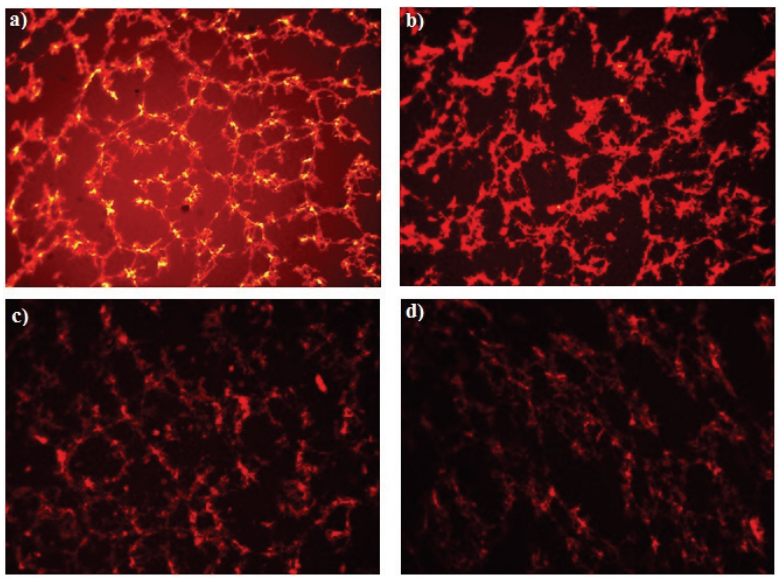

Figure 1 - Images of $3 \%$ polymer and nanoclay modified bitumen samples (10x) (a) 3\% SBS modified bitumen sample (b) 3\% SBS + 2\% Hal modified bitumen sample

(c) $3 \% \mathrm{SBS}+4 \%$ Hal modified bitumen sample

(d) $3 \% \mathrm{SBS}+2 \%$ Sep modified bitumen sample
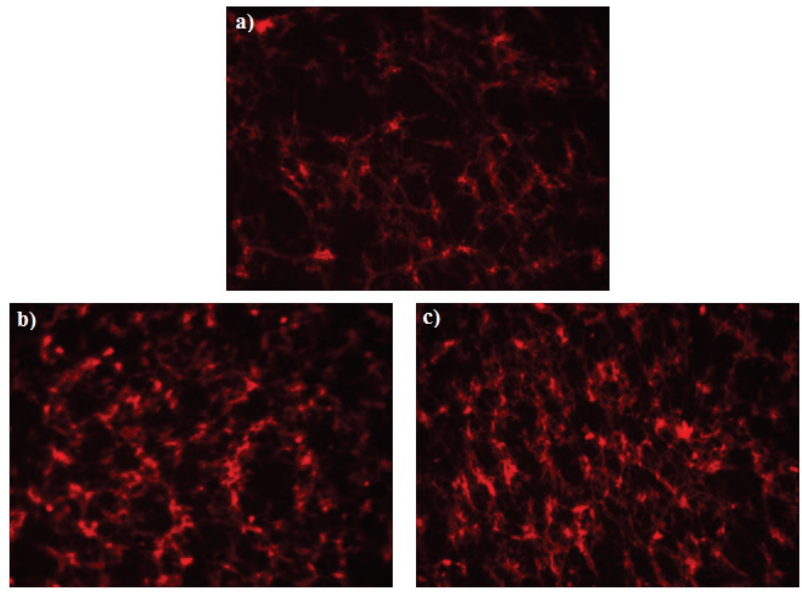

Figure 2 - Images of 5\% polymer and nanoclay modified bitumen samples (10x) (a) 5\% SBS modified bitumen sample (b) 5\% SBS + 2\% Hal modified bitumen sample (c) $5 \%$ SBS $+4 \%$ Hal modified bitumen sample

As seen in Figure 2.a, b and c, 5\% PMB samples, more intensive bonds were formed, dispersion and occupied area of additives were increased with the usage of nanoclays in the PMB is shown by Figure 2.a, b and c. Similarly, due to the insufficient dispersion amount, the images of 5\% SBS $+2 \%$ Sep and 5\% SBS $+4 \%$ Sep modified bitumen samples were not obtained. 


\subsubsection{Dynamic Shear Test Results}

Unaged and RTFOT aged bitumens were exposed to oscillatiion by DSR at $10 \mathrm{rad} / \mathrm{s}$ frequency $(1.59 \mathrm{~Hz})$ for determining upper critical temperature for PG system. The initial temperature values were set to $52^{\circ} \mathrm{C}$ and $64^{\circ} \mathrm{C}$ for respectively unaged and short term (RTFOT) aged bitumens with increments of $6^{\circ} \mathrm{C}$. The upper critical temperatures were specified for each sample according to $\mathrm{G}^{*} / \sin \delta$ results. The temperature is indicated the upper critical temperature at $\mathrm{G}^{*} / \sin \delta$ is $1.0 \mathrm{kPa}$ for unaged bitumen, and $\mathrm{G}^{*} / \sin \delta$ is $2.2 \mathrm{kPa}$ for short term aged bitumen sample [24]. The upper critical temperatures for each bitumens are seen in Table 6.

Table 6 - Determination of PG upper critical temperatures for base and modified bitumen samples

\begin{tabular}{|c|c|c|c|c|}
\hline \multirow{2}{*}{ Type of Bitumen } & \multirow{2}{*}{$\begin{array}{c}\text { Temperature } \\
\left({ }^{\circ} \mathrm{C}\right)\end{array}$} & \multicolumn{2}{|c|}{$\mathrm{G}^{*} / \sin \delta(\mathrm{Pa})$} & \multirow{2}{*}{$\begin{array}{c}\text { Upper Critical } \\
\text { Temperature }\end{array}$} \\
\hline & & Unaged & Aged & \\
\hline Base bitumen & 64 & 1622 & 4080 & $64-X$ \\
\hline \multirow{2}{*}{$3 \%$ SBS } & 70 & 1784 & 3611 & \multirow{2}{*}{$70-\mathrm{X}$} \\
\hline & 76 & 931.8 & 2111 & \\
\hline \multirow{2}{*}{$3 \%$ SBS + 2\% Hal } & 70 & 1834 & 4335 & \multirow{2}{*}{$70-\mathrm{X}$} \\
\hline & 76 & 892.4 & 2160 & \\
\hline \multirow{2}{*}{$3 \% \mathrm{SBS}+4 \%$ Hal } & 76 & 1059 & 4158 & \multirow{2}{*}{$76-X$} \\
\hline & 82 & 562.1 & 2107 & \\
\hline \multirow{2}{*}{$3 \%$ SBS + 2\% Sep } & 70 & 1877 & 3536 & \multirow{2}{*}{$70-X$} \\
\hline & 76 & 986 & 1730 & \\
\hline \multirow{2}{*}{$3 \%$ SBS + 4\% Sep } & 70 & 1601 & 4225 & \multirow{2}{*}{$70-X$} \\
\hline & 76 & 965.8 & 2027 & \\
\hline \multirow{3}{*}{$5 \%$ SBS } & 76 & 1776 & 3225 & \multirow{3}{*}{$76-X$} \\
\hline & 82 & 1184 & 1710 & \\
\hline & 88 & 769.1 & - & \\
\hline \multirow{3}{*}{$5 \%$ SBS + 2\% Hal } & 76 & 2018 & 3322 & \multirow{3}{*}{$76-X$} \\
\hline & 82 & 1101 & 1767 & \\
\hline & 88 & 612.8 & - & \\
\hline \multirow{3}{*}{$5 \%$ SBS + 4\% Hal } & 76 & 2115 & 2613 & \multirow{3}{*}{$76-X$} \\
\hline & 82 & 1353 & 1464 & \\
\hline & 88 & 909.9 & - & \\
\hline \multirow{3}{*}{$5 \%$ SBS + 2\% Sep } & 76 & 2331 & 3240 & \multirow{3}{*}{$76-X$} \\
\hline & 82 & 1410 & 1719 & \\
\hline & 88 & 904.6 & - & \\
\hline \multirow{3}{*}{$5 \%$ SBS + 4\% Sep } & 76 & 2180 & 3444 & \multirow{3}{*}{$76-X$} \\
\hline & 82 & 1410 & 1804.57 & \\
\hline & 88 & 938.2 & - & \\
\hline
\end{tabular}


It can be inferred from Table 6 that PG upper critical temperatures of modified bitumen samples are higher than base bitumen. The performance grades of modified bitumen samples have been risen one degree for 3\% SBS modified group, and two degrees for 5\% SBS modified group. The higher upper critical temperature is an indicator value of higher permanent deformation resistance.

The RTFOT aged bitumen samples were exposed to oscillation by DSR at low $(0.01 \mathrm{~Hz})$ and high $(10 \mathrm{~Hz})$ frequency levels at five temperatures ranging from $40^{\circ} \mathrm{C}$ to $80^{\circ} \mathrm{C}$ with $10^{\circ} \mathrm{C}$ increments. The variation of $\mathrm{G}^{*} / \sin \delta$ values of base and modified bitumens at two frequency values are presented in Figure 3 and Figure 4.

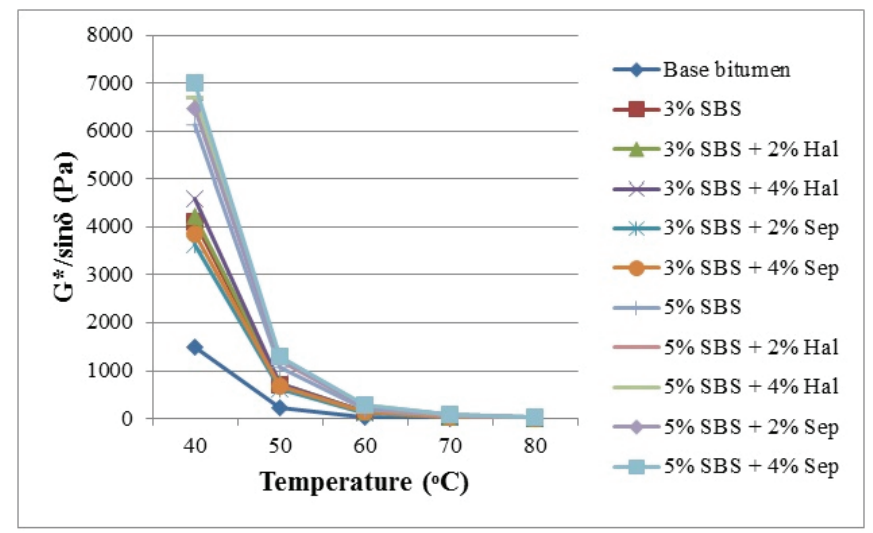

Figure $3-G^{*} /$ sin $\delta$ values of base and modified bitumen samples at $0.01 \mathrm{~Hz}$

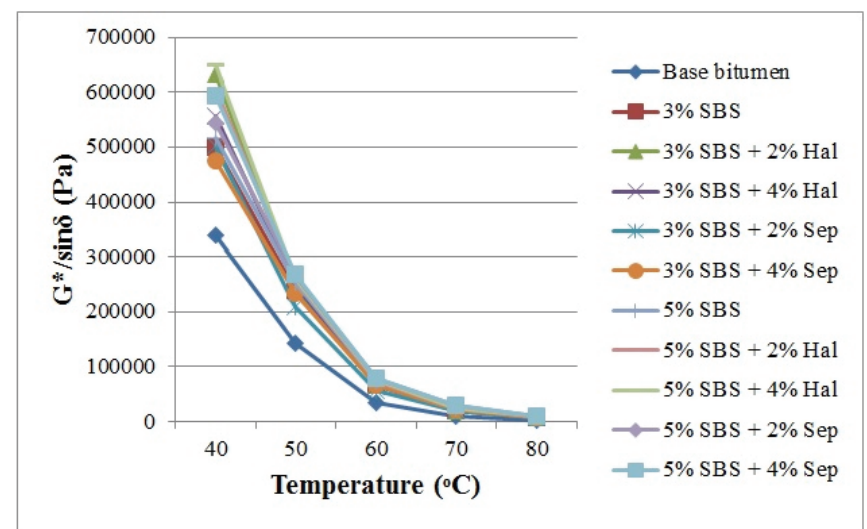

Figure $4-G^{*} /$ sin $\delta$ values of base and modified bitumen samples at $10 \mathrm{~Hz}$

As can be seen in Fig. 3 and Fig. 4, concerning all samples, $\mathrm{G}^{*} / \sin \delta$ values increase with decrease in temperature at two frequency values. The increase in $G^{*} / \sin \delta$ value specifies higher rutting performance. Furthermore, expectedly $\mathrm{G}^{*} / \sin \delta$ values increase with increasing 
frequency for all samples. This is owing to the rheological behavior of bitumen by reason of exhibiting elastic behaviour the bitumen under high frequency level or shorter loading times [42].

The rutting parameter of modified bitumen samples have been significantly increased at two different frequencies and five different temperatures according to the base bitumen. The $\mathrm{G}^{*} / \sin \delta$ values improved by addition of SBS into the base bitumen, have been increased by addition of nanoclays into the PMB. This case is evidently observed on modified bitumen samples containing 5\% SBS. 5\% SBS $+4 \%$ Sep has the highest $\mathrm{G}^{*} / \sin \delta$ value at low frequency and $5 \%$ SBS $+4 \%$ Hal has the highest $\mathrm{G}^{*} / \sin \delta$ value at high frequency among the aged bitumen samples. These modified bitumen samples are the most resistant samples even as a result of expose to aging.

\subsubsection{Zero Shear Viscosity Test Results}

The results of ZSV for all bitumen samples obtained by DSR performed with creep mode are illustrated in Figure 5.

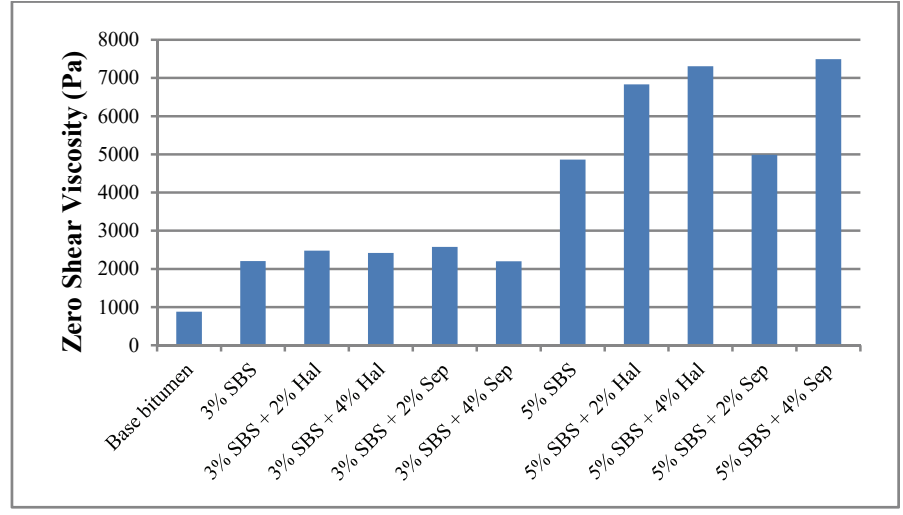

Figure 5 - ZSV values for base and modified bitumen samples

As seen in Figure 5, 5\% SBS + 4\% Sep sample has the highest ZSV value among the bitumen samples. As a result of the using of nanoclay in the group containing both $3 \%$ and $5 \%$ polymer additive, an increase in ZSV was observed compared to the only SBS modified bitumen. Higher ZSV values indicate higher resistance against permanent deformation during long term loading [34]. It is expected from modified bitumens that exposing the least deformation and giving the highest value of $\mathrm{ZSV}$.

\subsubsection{Multiple Stress Creep Recovery Test Results}

The percent recovery $(\mathrm{R})$, the non-recoverable compliance $\left(\mathrm{J}_{\mathrm{nr}}\right)$ for 100 and $3200 \mathrm{~Pa}$, stress sensibility and also the percent differences in non-recoverable compliances $\left(\mathrm{J}_{\mathrm{nr}-\mathrm{diff}}\right)$ of the bitumen samples are seen in Table 7 . 
The percentage of return of bitumen samples under a certain load has increased considerably by modifying the base bitumen. When the load on the sample was removed, it was found that the highest recovery was provided by the 5\% SBS modified bitumen sample, followed by $5 \% \mathrm{SBS}+4 \%$ Sepiolite modified bitumen sample. This is thought to be due to the fact that the nanoclays do not have a flexible structure.

The higher compliance value $\left(\mathrm{J}_{\mathrm{nr}}\right)$ indicates that the bitumen samples will be exposed to further deformation under a certain loading condition. Lower $\mathrm{J}_{\mathrm{nr}}$ values specify lower sensibility to rutting. Base bitumen has the highest compliance value at two stress levels (100 and $3200 \mathrm{~Pa}$ ) as expected. This shows that the base bitumen is the most susceptible bitumen type to rutting. However, 5\% SBS modified bitumen sample has the lowest compliance values.

The stress sensibility of the bitumen samples was defined with the differences as percent for non-recoverable compliances $\left(\mathrm{J}_{\mathrm{nr}-\mathrm{diff}}\right)$. When the stress level is increased from 100 to 3200 $\mathrm{Pa}$, the non-recoverable compliance value specifies the percentage of increment about $\mathrm{J}_{\mathrm{nr}}$ of the sample.

Table 7 - MSCR test results for base and modified bitumen samples

\begin{tabular}{|c|c|c|c|c|c|c|}
\hline $\begin{array}{c}\text { Bitumen } \\
\text { Type }\end{array}$ & $\begin{array}{l}\text { R@100 } \\
\text { Pa }(\%)\end{array}$ & $\begin{array}{c}\text { R@3200 } \\
\text { Pa (\%) }\end{array}$ & $\begin{array}{c}\mathbf{J}_{\mathrm{nr}} \\
@ \mathbf{1 0 0} \\
\mathbf{P a} \\
\end{array}$ & $\begin{array}{c}\mathbf{J}_{\mathrm{nr}} \\
\text { a3200 } \\
\mathbf{P a}\end{array}$ & $\begin{array}{c}\mathbf{J}_{\text {nr-diff. }} \\
(\%)\end{array}$ & $\begin{array}{c}\text { Stress } \\
\text { Sensibility }\end{array}$ \\
\hline $\begin{array}{c}\text { Base } \\
\text { Bitumen }\end{array}$ & 6.493 & 3.167 & 1.126 & 1.183 & 5.061 & 0.051 \\
\hline $3 \%$ SBS & 18.044 & 13.474 & 0.461 & 0.499 & 8.104 & 0.081 \\
\hline $\begin{array}{c}3 \% \text { SBS + } \\
2 \% \text { Hal }\end{array}$ & 20.41 & 14.513 & 0.459 & 0.512 & 11.541 & 0.115 \\
\hline $\begin{array}{c}3 \% \text { SBS + } \\
4 \% \text { Hal }\end{array}$ & 18.523 & 14.325 & 0.395 & 0.418 & 5.794 & 0.058 \\
\hline $\begin{array}{c}3 \% \text { SBS + } \\
2 \% \text { Sep } \\
\end{array}$ & 18.725 & 13.532 & 0.472 & 0.514 & 8.849 & 0.088 \\
\hline $\begin{array}{c}3 \% \text { SBS + } \\
4 \% \text { Sep }\end{array}$ & 16.834 & 12.467 & 0.496 & 0.534 & 7.751 & 0.078 \\
\hline $5 \%$ SBS & 45.437 & 41.956 & 0.104 & 0.111 & 6.345 & 0.063 \\
\hline $\begin{array}{c}5 \% \text { SBS + } \\
2 \% \text { Hal } \\
\end{array}$ & 39.793 & 35.398 & 0.159 & 0.174 & 9.340 & 0.093 \\
\hline $\begin{array}{c}5 \% \text { SBS + } \\
4 \% \text { Hal }\end{array}$ & 42.017 & 36.705 & 0.16 & 0.181 & 12.509 & 0.125 \\
\hline $\begin{array}{c}5 \% \text { SBS + } \\
2 \% \text { Sep } \\
\end{array}$ & 30.035 & 25.248 & 0.197 & 0.212 & 8.100 & 0.081 \\
\hline $\begin{array}{c}5 \% \text { SBS + } \\
4 \% \text { Sep }\end{array}$ & 49.505 & 40.478 & 0.171 & 0.205 & 19.844 & 0.198 \\
\hline
\end{tabular}


It determines the sensibility against rutting when sudden loadings due to heavy traffic are implemented on pavement or extraordinary high temperatures are observed. This percent difference value is a measurement of the sensibility to the increase in the stress level; hence lower values are defined by a less stress sensible material $[43,44]$. The $\mathrm{J}_{\mathrm{nr}-\mathrm{diff}}$ value and stress sensibility are high for 5\% SBS $+4 \%$ Sep sample, thus this modified bitumen is highly stress sensible at the stress level of $3200 \mathrm{~Pa}$.

In addition, according to the MSCR test results, a new performance classification called PG Plus became a current issue. In this new classification method, the Jnr value at $3.2 \mathrm{kPa}$ (3200 $\mathrm{Pa}$ ) loading is taken into account at the temperature at which the test is performed. There are four traffic conditions according to the performance classification and named $\mathrm{S}$ (Standard: < $4.0 \mathrm{kPa}^{-1}$ and standard traffic loading), $\mathrm{H}$ (Heavy: $<2.0 \mathrm{kPa}^{-1}$ or slow moving traffic loading), $\mathrm{V}$ (Very Heavy: $<1.0 \mathrm{kPa}^{-1}$ or standing traffic loading) and $\mathrm{E}$ (Extreme Heavy: $<0.5 \mathrm{kPa}^{-1}$ ESALs and standing traffic loading) $[45,46]$. PG Plus grades determined according to $\mathrm{J}_{\mathrm{nr}}$ values under $3200 \mathrm{~Pa}$ loading obtained from MSCR test are presented in Table 8.

Table 8 - MSCR letter grades of base and modified bitumen samples

\begin{tabular}{|c|c|c|c|}
\hline Bitumen Type & $\begin{array}{c}\text { Superpave Performance } \\
\text { Grade }\end{array}$ & $\begin{array}{c}J_{n r} @ 3200 \\
\left(\mathrm{kPa}^{-1}\right)\end{array}$ & PG Plus Grade \\
\hline Base Bitumen & PG 64 & 1.183 & PG $60 \mathrm{H}$ \\
\hline $3 \%$ SBS & PG 70 & 0.499 & PG $60 \mathrm{E}$ \\
\hline $\begin{array}{c}3 \% \text { SBS + 2\% } \\
\text { Hal }\end{array}$ & PG 70 & 0.512 & PG $60 \mathrm{~V}$ \\
\hline $\begin{array}{c}\text { 3\% SBS + 4\% } \\
\text { Hal }\end{array}$ & PG 70 & 0.418 & PG $60 \mathrm{E}$ \\
\hline $\begin{array}{c}\text { 3\% SBS + 2\% } \\
\text { Sep }\end{array}$ & PG 70 & 0.514 & PG $60 \mathrm{~V}$ \\
\hline $\begin{array}{c}3 \% \text { SBS }+4 \% \\
\text { Sep } \\
\end{array}$ & PG 70 & 0.534 & PG $60 \mathrm{~V}$ \\
\hline $5 \%$ SBS & PG 76 & 0.111 & PG $60 \mathrm{E}$ \\
\hline $\begin{array}{c}5 \% \text { SBS + 2\% } \\
\text { Hal }\end{array}$ & PG 76 & 0.174 & PG $60 \mathrm{E}$ \\
\hline $\begin{array}{c}5 \% \text { SBS }+4 \% \\
\text { Hal }\end{array}$ & PG 76 & 0.181 & PG $60 \mathrm{E}$ \\
\hline $\begin{array}{c}5 \% \text { SBS + 2\% } \\
\text { Sep }\end{array}$ & PG 76 & 0.212 & PG $60 \mathrm{E}$ \\
\hline $\begin{array}{l}5 \% \text { SBS + 4\% } \\
\text { Sep }\end{array}$ & PG 76 & 0.205 & PG $60 \mathrm{E}$ \\
\hline
\end{tabular}

PG Plus grades increased as expected as a result of adding additives to base bitumen according to the results in Table 8 . Although the class of 3\% SBS modified bitumen is E, it has fallen to $\mathrm{V}$ class with the addition of $2 \%$ halloysite, but its values are very close to each other. The PG Plus grade rose again to E class with increase of halloysite amount and the rate 
was $4 \%$. As a result of the addition of sepiolite, there was no change in both ratios and remained constant in the $\mathrm{V}$ class. As a result of the $5 \%$ SBS modification, the grade rising to E class has also maintained its place with the addition of nanoclays. This MSCR letter implies that the sample can resist deformations even under extremely heavy traffic conditions.

\section{CONCLUSION}

As a result of the study, the conventional, rheological bitumen tests and examination of morphological structure have been utilized to evaluate the difference in the properties and performance of SBS modified bitumens containing nanoclay additives.

Conventional bitumen tests performed on two different ratios of SBS modified bitumen samples (3\% and $5 \%)$ and each concentration containing $2 \%, 4 \%$ halloysite and sepiolite. A considerable decrease in penetration and increase in softening point temperatures of modified bitumen samples have been observed for all concentrations of additives compared to base bitumen. The decrease in penetration has been increased some more as a result of nanoclay addition into the PMB. The increase in softening point temperatures has showed a change according to the polymer ratio between PMBs containing nanoclays. The softening point temperatures have been increased for 3\% SBS modified bitumen samples but have not been changed for $5 \%$ SBS modified bitumens.

It can be deduced from the viscosity test results that the addition of nanoclays increases viscosity for two temperature values. The viscosity values have been increased with increasing of nanoclay content. The storage stability results have been improved with addition of nanoclays especially in low SBS ratio. The improvement in storage stability has been reduced with increasing of SBS percentage.

The PG upper critical temperatures of modified bitumen samples are higher than base bitumen and advanced at least one degree as a result of the modification. The performance grade has increased two degrees in some modified bitumens. Higher upper critical temperature value indicates higher resistance against permanent deformation.

The results of DSR, $\mathrm{G}^{*} / \sin \delta$ values have increased with an increment in frequency regarding all samples. Based on the $\mathrm{G}^{*} / \mathrm{sin} \delta$ values at low and high frequencies, it has been seen that modification of base bitumen with SBS enhances the performance of base bitumen to rutting. Additionally, the rutting resistance of modified bitumens has been improved with using nanoclay additives in SBS modified bitumen samples.

According to ZSV results, it is deduced that increase of polymer percentage and addition of nanoclays improve rutting performance of modified bitumens.

Based on MSCR test results, especially high percentage of polymer is provided high recovery values. Besides, addition of nanoclays slightly decreases the recovery values because of low elastic behaviour of nanoclays. Bitumens have high percent recovery and low nonrecoverable compliance values are more resistant to rutting under loading and unloading cycles. Otherwise the MSCR letters imply that polymer modified bitumen samples 
containing nanoclays could remain resistant to deformations even under heavy and extreme heavy traffic conditions.

The results showed that nanoclays could be used as additives for improving physical and rheological properties of PMB samples. When all test results were evaluated with the limitation of storage stability results, it was seen that the addition of nanoclay in 3\% SBS modified bitumens was more appropriate. This also revealed the result that determining an optimum value for the polymer ratio is very important. It is recommended that production in more detailed combinations for nanocomposites and further performance analyses are needed.

\section{Acknowledgement}

This research was sponsored by the Scientific Research Project Office of Manisa Celal Bayar University with the project number 2014-069 for which the authors are greatly indebted. The authors are also thankful to the Graduate School of Natural and Applied Sciences of Dokuz Eylul University for its support.

\section{Symbols}

$\mathrm{G}^{*} \quad$ : complex shear modulus

G' : shear storage modulus

G" $\quad$ : shear loss modulus

$\delta \quad$ : phase angle

$\mathrm{G}^{*} / \sin \delta$ : rutting resistance parameter

$\mathrm{G}^{*} \cdot \sin \delta$ : fatigue cracking performance parameter

$\Delta \mathrm{t} \quad: 900$ seconds time interval

$\Delta \mathrm{J} \quad$ : difference between $\mathrm{J}_{\mathrm{f}}$ and $\mathrm{J}_{15}$

$\mathrm{J}_{\mathrm{f}} \quad$ : compliance measured at the end of the 30 minutes

$\mathrm{J}_{15} \quad$ : compliance measured last 15 minutes before lifting the loading

$\mathrm{J}_{\mathrm{nr}} \quad$ : non-recoverable creep compliance

$\%$ : percent recovery

$\mathrm{J}_{\mathrm{nr}, \text { diff }} \quad$ : difference in $\mathrm{J}_{\mathrm{nr}}$

\section{References}

[1] Polacco, G., Stastna, J., Biondi, D., Zanzotto, L., Relation between polymer architecture and nonlinear viscoelastic behavior of modified asphalts, Current Opinion in Colloid \& Interface Science, 11(4), 230-245, 2006. 
[2] Polacco G., Křŕž, P., Filippi, S., Stastna, J., Biondi, D., Zanzotto, L., Rheological properties of asphalt/SBS/clay blends, European Polymer Journal, 44(11), 3512-3521, 2008.

[3] Ahmedzade, P., Fainleib, A., Günay, T., Grigoryeva, O., Geri Dönüştürülmüş Atık Polipropilenin Bitümlü Bağlayıcılarda Kullanılması, Teknik Dergi, 456, 7497-7513, 2016.

[4] Aglan, H., Othman, A., Figueroa, L., Rollings, R., Effect of styrene-butadiene-styrene block copolymer on fatigue crack propagation behavior of asphalt concrete mixtures, Transportation Research Record, 1417, 178-86, 1993.

[5] Kumar P., Chandra S., Bose S., Strength characteristics of polymer modified mixes, International Journal of Pavement Engineering, 7(1), 63-71, 2006.

[6] Tayfur, S., Ozen, H., Aksoy, A., Investigation of rutting performance of asphalt mixtures containing polymer modifiers, Construction and Building Materials, 21(2), 328-37, 2007.

[7] Bulatović, V. O., Rek, V., Marković, K. J., Effect of polymer modifiers on the properties of bitumen, Journal of Elastomers \& Plastics, 46(5), 448-469, 2014.

[8] Alatas, T., Yilmaz, M., Kuloglu, N., Cakiroglu, M., Geckil, T., Investigation of Shear Complex Modulus and Phase Angle Values of Short and Long-term Aged Polymer Modified Bitumens at Different Frequencies, KSCE Journal of Civil Engineering, 18(7), 2093-2099, 2014.

[9] Galooyak, S. S., Dabir, B., Nazarbeygi, A. E., Moeini, A., Rheological properties and storage stability of bitumen/SBS/montmorillonite composites, Construction and Building Materials, 24(3), 300-307, 2010.

[10] Golestani, B., Nejad, F. M., Galooyak, S. S., Performance evaluation of linear and nonlinear nanocomposite modified asphalts, Construction and Building Materials, 35, 197-203, 2012.

[11] Topal. A., Sureshkumar, M. S., Sengoz, B., Polacco, G., Rheology and microstructure of polymer-modified asphalt nanocomposites, International Journal of Materials Research, 103(10), 1271-1276, 2012.

[12] Yao, H., You, Z., Li, L. Goh, S. W., Lee, C. H., Yap, Y. K., Rheological properties and chemical analysis of nanoclay and carbon microfiber modified asphalt with Fourier transform infrared spectroscopy, Construction and Building Materials, 38, 327-337, 2013.

[13] Jasso, M., Bakos, D., MacLeod, D., Zanzotto, L., Preparation and properties of conventional asphalt modified by physical mixtures of linear SBS and montmorillonite clay, Construction and Building Materials, 38, 759-765, 2013.

[14] Sureshkumar, M. S., Filippi, S., Polacco, G., Kazatchkov, I., Stastna, J., Zanzotto, L., Internal structure and linear viscoelastic properties of EVA/asphalt nanocomposites, European Polymer Journal, 46, 621-633, 2010. 
[15] Jasso, M., Bakos, D., Stastna, J., Zanzotto, L., Conventional asphalt modified by physical mixtures of linear SBS and montmorillonite, Applied Clay Science, 70, 37-44, 2012.

[16] Merusi, F., Giuliani, F., Polacco, G., Linear viscoelastic behaviour of asphalt binders modified with polymer/clay nanocomposites, Procedia-Social and Behavioral Sciences, 53, 335-345, 2012.

[17] Liu, G., Wu, S., Van de Ven, M., Yu, J., Molenaar, A., Structure and artificial ageing behavior of organo montmorillonite bitumen nanocomposites, Applied Clay Science, 72, 49-54, 2013.

[18] Yao, H., You, Z., Li, L., Shi, X., Goh, S.W., Mills-Beale, J., Wingard, D., Performance of asphalt binder blended with non-modified and polymer-modified nanoclay, Construction and Building Materials, 35, 159-170, 2012.

[19] You, Z., Mills-Beale, J., Foley, J. M., Roy, S., Odegard, G. M., Dai, Q., Goh, S. W., Nanoclay-modified asphalt materials: Preparation and characterization, Construction and Building Materials, 25 (2), 1072-1078, 2011.

[20] Galooyak, S. S., Dabir, B., Nazarbeygi, A. E., Moeini, A., Berahman, B., The effect of nanoclay on rheological properties and storage stability of SBS modified bitumen, Petroleum Science and Technology, 29(8), pp. 850-859, 2011.

[21] ASTM D5-06., Standard test method for penetration of bituminous materials, West Conshohocken (PA), USA: American Society for Testing and Materials, 2006.

[22] ASTM D36-06., Test method for softening point of bitumen (ring-and-ball apparatus), West Conshohocken (PA), USA: American Society for Testing and Materials, 2006.

[23] ASTM D4402-06., Standard test method for viscosity determination of asphalt at elevated temperatures using a rotational viscometer, West Conshohocken (PA), USA: American Society for Testing and Materials, 2002.

[24] ASTM D2872-12., Standard test method for effect of heat and air on a moving film of asphalt (Rolling Thin-Film Oven Test), West Conshohocken (PA), USA: American Society for Testing and Materials, 2012.

[25] Kraton ${ }^{\circledR}$ D1101 A Polymer., Data document, 2012.

[26] Şengöz, B., Topal, A., G. Iş1kyakar, Morphology and image analysis of polymer modified bitumens, Construction and Building Materials, 23, 1986-1992, 2009.

[27] Topal, A., Sureshkumar, M. S., Şengöz, B., Polacco, G., Rheology and microstructure of polymer-modified asphalt nanocomposites, International Journal of Materials Research, 103, 1271-1276, 2012.

[28] EN 13399., Bitumen and bituminous binders-Determination of storage stability of modified bitumen, Avenue Marnix 17, B-1000. Brussels: European Committee for Standardization, Management Centre, 2010.

[29] Chen, J., Liao, M., Shiah, M., Asphalt modified by SBS triblock copolymer morphology and model, Journal of Materials in Civil Engineering, 14(3), 224-229, 2002. 
[30] Airey, G. D., Rheological evaluation of EVA polymer modified bitumen, Journal of Construction and Building Materials, 16(8), pp. 473-487, 2002.

[31] Asphalt Institute., Superpave performance graded asphalt binder specification and testing, Third Edition, Asphalt Institute, Lexington, United States, 2003.

[32] De Visscher, J., Soenen, H., Vanelstraete, A., Redelius, P. A., Comparison of the zero shear viscosity from oscillation tests and the repeated creep test, $3^{\text {rd }}$ Eurasphalt \& Eurobitume Congress, Vienna, Austria, 2004.

[33] Gungor, A. G., Saglik, A., Evaluation of rutting performance of neat and modified binders using zero shear viscosity, $5^{\text {th }}$ Eurasphalt \& Eurobitume Congress, Istanbul, Turkey, 2012.

[34] CEN TS 15325., Bitumen and bituminous binders: Determination of zero shear viscosity (ZSV) using a shear stress rheometer in creep mode, European Committee for Standardization, Brussels, 2008.

[35] Laukkanen, O., Pellinen, T., Makowska, M., Exploring the observed rheological behavior of in-situ aged and fresh bitumen employing the colloidal model proposed for bitumen, Multi-Scale Modeling and Characterization of Infrastructure Materials, 8, 185-197, 2013.

[36] Saboo N., Kumar P., A study on creep and recovery behavior of asphalt binders, Construction and Building Materials, 96, pp. 632-640, 2015.

[37] ASTM D7405-08., Standard test method for multiple stress creep and recovery (MSCR) of asphalt binder using a dynamic shear rheometer, West Conshohocken (PA), USA: American Society for Testing and Materials, 2008.

[38] Yilmaz, M., Ahmedzade, P., Investigation of pure and SBS modified bituminous binder properties after short term ageing by using two different ageing methods, Journal of The Faculty of Engineering and Architecture of Gazi University, 23(3), 569-575, 2008.

[39] Ouyang, C., Wang, S., Zhang, Y., Zhang, Y., Thermo-rheological properties and storage stability of SEBS/kaolinite clay compound modified asphalts, European Polymer Journal, 42, 446-457, 2006.

[40] Baochang, Z., Man, X., Dewen, Z., Huixuan, Z., Baoyan, Z., The effect of styrenebutadiene-rubber/montmorillonite modification on the characteristics and properties of asphalt, Construction and Building Materials, 23, 3112-3117, 2009.

[41] Yılmaz, M., Kök, B. V., Kuloğlu, N., Alataş, T., Experimental investigation of the storage stability and rheological properties of elastomeric polymer modified bituminous binders, DEÜ Mühendislik Fakültesi Fen Ve Mühendislik Dergisi, 15(1), 67-77, 2013.

[42] Whiteoak D., Read J. M., The shell bitumen handbook, Fifth Edition, Thomas Telford Publishing, London, UK, 2003.

[43] Oner, J., Sengoz, B., Investigation of rheological effects of waxes on different bitumen sources, Road Materials and Pavement Design, 18(6), 1269-1287, 2017. 
[44] Sengoz, B., Bagayogo, L., Oner, J., Topal, A., Investigation of rheological properties of transparent bitumen, Construction and Building Materials, 154, 1105-1111, 2017.

[45] Horan, B., Engineer, R.: Multiple Stress Creep Recovery (MSCR) Task Force, Asphalt Institute - Virginia Office, SEAUPG Annual Meeting, Savannah GA, 2011.

[46] Oner, J., Rheological characteristics of bitumens prepared with process oil, Gradevinar, 71(7), 559-569, 2019. 